\title{
Adsorption of acetaldehyde onto carbide-derived carbon modified by oxidation
}

\author{
Hongyan Wang ${ }^{a}$, Yifei Sun ${ }^{a}$, Tianle Zhu ${ }^{\mathrm{a}, *}$, Wenzheng Wang ${ }^{\mathrm{a}}$, Hua Deng ${ }^{\mathrm{b}}$ \\ ${ }^{a}$ School of Chemistry and Environment, Beijing Key Laboratory of Bio-Inspired Energy Materials and Devices, Beihang University, Beijing 100191, China \\ ${ }^{\mathrm{b}}$ Research Center for Eco-Environmental Sciences, Chinese Academy of Sciences, Beijing 100085, China
}

\section{H I G H L I G H T S}

- The influence of oxidation modification on the properties of CDC was studied.

- The relationship between the properties and adsorption performance was studied.

- The acidic oxygen-containing groups in CDC increase the adsorption capacities.

- DFT predicts the role of acidic oxygen-containing groups for adsorption.

\section{A R T I C L E I N F O}

\section{Article history:}

Received 30 January 2015

Received in revised form 21 March 2015

Accepted 23 March 2015

Available online 28 March 2015

\section{Keywords:}

Adsorption

Acetaldehyde

Carbide-derived carbon

Oxidation

Density functional theory

\begin{abstract}
A B S T R A C T
The adsorption of acetaldehyde over carbide-derived carbon (CDC) modified with nitric acid, hydrogen peroxide, or air was investigated. The physicochemical properties of the original and modified CDCs were characterized by $\mathrm{N}_{2}$ adsorption, Fourier transform infrared spectrometer, temperature programmed desorption and X-ray photoelectron spectroscopy. It was observed that the oxidation modification, especially the nitric acid treatment, could significantly enhance the adsorption performance of CDC for acetaldehyde. The increase of acidic oxygen-containing groups like carboxylic acids and anhydrides in the modified CDCs results in the increase of adsorption performance. The density functional theory calculations and in situ Diffuse Reflectance Infrared Fourier Transform Spectroscopy show that these acidic oxygen-containing groups display strong hydrogen bonding interactions with acetaldehyde molecule, leading to the enhanced adsorption performance.
\end{abstract}

(C) 2015 Published by Elsevier B.V.

\section{Introduction}

The air quality of cabins such as manned spacecraft and submarine has been a great concern since the cabins are in airtight states. A healthy and safe atmosphere is a fundamental requirement for the crew members' health, the quality of their work, and even the safety of airtight cabins. To meet this requirement, the development of highly reliable and efficient life-support system is required. A key function of the system is the removal of trace volatile organic compounds (VOCs), which are introduced through the offgassing of spacesuit materials, or through the metabolic production (e.g. breathing, sweating, etc.) of crew members. These VOCs can be hazardous to crew members' health with side effects ranging from headaches to heart damage, based on the exposure level and duration [1-4]. Therefore, the removal of VOCs is essential for improving cabin air quality.

Adsorption by activated carbon (AC) is a common approach for VOC removal in cabins and works well for macromolecule organic

\footnotetext{
* Corresponding author.
}

compounds like aromatics [2,3]. However, those highly volatile, low molecular weight organic compounds such as acetaldehyde are typically poorly adsorbed onto the traditional AC. In our previous study, we found out that a new type of porous carbon material, carbide-derived carbon (CDC), could adsorb much more acetaldehyde than commercial activated carbons and appears as a promising adsorbent in cabins due to its unique pore properties [5]. However, it is well known that the adsorption performance of an adsorbent such as carbon material depends not only on its pore properties but also on its surface chemistry [6]. The surface chemistry of carbon is related to the presence of heteroatoms (e.g. hydrogen, oxygen, nitrogen, sulfur and phosphorus), which are bonded at the edges of the graphite-like layers and form organic functional groups such as carboxylic acids, anhydride, lactones, phenols, amines, nitro compounds, and phosphates [7]. These functional groups, especially oxygen functional groups, have significant influence on the performance of $\mathrm{AC}$ as adsorbent, because they can promote the polarity and wettability of carbon and consequently benefit the adsorption performance, especially for the polar organic compounds [8]. Considering the huge 
influence of oxygen functional groups on the performance of carbon materials, methods allowing the control of both the nature and concentration of oxygen functional groups for specific applications have been studied and the oxidation treatment is the most commonly used method. The oxidation process of carbon materials can be carried out in the gas phase (dry method) using oxygen, air, or ozone $[9,10]$, or in the liquid phase (wet method) by means of $\mathrm{H}_{2} \mathrm{O}_{2}, \mathrm{HNO}_{3}$, $\left(\mathrm{NH}_{4}\right)_{2} \mathrm{~S}_{2} \mathrm{O}_{8}$, etc. [9,11] to introduce surface oxygen complexes on the carbon surface. There are many factors that are responsible for the nature of surface groups created during oxidation treatment, such as the type of the oxidant, the oxidation temperature and time. Besides, the characteristics of carbon materials including origin and history of preparation also play an important part $[12,13]$. However, to the best of our knowledge, the influence of oxidation modification on the pore properties and surface chemistry of CDC, and the relationship between these properties and adsorption performance, have not been systematically studied. The unique structure of $\mathrm{CDC}$ may yield surface properties that are different from those of most other carbon materials, which may affect its adsorption performance significantly.

For these reasons, the main objective of this study was to investigate the effect of oxidation modification, by means of liquid phase oxidation $\left(\mathrm{HNO}_{3}\right.$ and $\left.\mathrm{H}_{2} \mathrm{O}_{2}\right)$ and gas phase oxidation (air), on the properties and adsorption performance of $\mathrm{CDC}$ for acetaldehyde. The pore structure and surface chemistry of CDCs were characterized by $\mathrm{N}_{2}$ adsorption, fourier transform Infrared Spectrometer (FT-IR), temperature programmed desorption (TPD) and X-ray photoelectron spectroscopy (XPS). Meanwhile, the adsorption phenomena were simulated by the density functional theory (DFT) and compared with the experimental results.

\section{Experimental}

\subsection{Preparation of original and modified CDCS}

The original CDC was prepared by selective etching Ti from commercial TiC precursor (99.5\% purity, 30-40 mesh, Zhuzhou GuangYuan Cemented Material Co., Ltd, PR China) by freshly prepared chlorine. The chlorination equipment and methodology is well described elsewhere [5]. The TiC precursor was placed in a horizontal quartz tube furnace. The tube was purged with $\operatorname{argon}(\mathrm{Ar})$ at room temperature for $30 \mathrm{~min}$ to remove air, and then heated to $700{ }^{\circ} \mathrm{C}$ at the heating rate of $10^{\circ} \mathrm{C} \mathrm{min}-1$. Once the desired temperature was reached, the Ar flow was stopped and chlorine gas was passed through the tube furnace at a flow rate of about $30 \mathrm{ml} \mathrm{min}^{-1}$ for $2 \mathrm{~h}$, and then the furnace was cooled down to room temperature under Ar purge.

Subsequently, the $\mathrm{CDC}$ was oxidized in the liquid phase $\left(\mathrm{HNO}_{3}\right.$, $\mathrm{H}_{2} \mathrm{O}_{2}$ ) and gas phase (air). In the first two cases, $1 \mathrm{~g}$ of CDC was mixed with $10 \mathrm{ml}$ of $\mathrm{HNO}_{3}\left(5 \mathrm{~mol} \mathrm{ml} \mathrm{L}{ }^{-1}\right.$ ) or $\mathrm{H}_{2} \mathrm{O}_{2}(30 \%)$ solutions for $12 \mathrm{~h}$ at room temperature. The oxidized CDCs were washed with deionized water until neutral $\mathrm{pH}$, and dried at $105^{\circ} \mathrm{C}$ for $3 \mathrm{~h}$. The samples were designated as CDC-N and CDC-H, respectively. For the gas phase oxidation, the $\mathrm{CDC}$ was heated in the tube furnace from room temperature to $300{ }^{\circ} \mathrm{C}$ under the constant flow of $\mathrm{N}_{2}$, and then, the reactor was kept at this temperature under a flow of air for $1 \mathrm{~h}$. After that, the furnace was cooled down to room temperature in $\mathrm{N}_{2}$ and the sample obtained was denoted as CDC-A. All samples prepared were kept in glove box under $\mathrm{N}_{2}$ atmosphere, before subsequent experiments.

\subsection{Evaluation of adsorption performance}

The details of the adsorption test were well described in previous work [5] and only brief description was given here. The acetaldehyde was prepared by bubbling air into liquid acetaldehyde that was kept at $10^{\circ} \mathrm{C}$ with a thermostat water bath. Then, the acetaldehyde was mixed with diluent gas at a gas-mixing chamber to obtain the desired concentration $\left(23 \pm 0.5 \mathrm{mg} \mathrm{m}^{-3}\right)$, which was monitored by an online gas chromatograph (GC-17A, Shimadzu) with a flame ionization detector. The adsorption measurement of acetaldehyde was performed in a continuous flow fixed-bed quartz reactor (i.d. $=10 \mathrm{~mm}$ ) containing $0.26 \mathrm{~g}$ adsorbent, operating under atmospheric pressure at $25^{\circ} \mathrm{C}$. Relative humidity of the reaction gas was $35 \pm 5 \%$. It was noteworthy that prior to all measurements, samples were degassed at $120^{\circ} \mathrm{C}$ in flow of $\mathrm{N}_{2}$ for $1 \mathrm{~h}$ to clear the possible adsorbates.

\subsection{Characterizations of adsorbents}

The porosity of CDCs was characterized by $\mathrm{N}_{2}$ adsorption at $-196^{\circ} \mathrm{C}$ using a QuadraSorb Station 1 instrument. Prior to the $\mathrm{N}_{2}$ adsorption, the samples were first outgassed at $200^{\circ} \mathrm{C}$ for more than $12 \mathrm{~h}$. The specific surface area (SSA) was calculated by using the Langmuir method. The micropore volumes $\left(V_{\text {mic }}\right)$ were determined by the t-method. The pore size distributions (PSDs) were determined by using the nonlocal density functional theory method for slit shaped pores provided by Quantachrome data reduction software.

The FT-IR measurements were performed on a FT-IR spectrometer (E55Xfra106, BRUKER, Germany) in the frequency range of $400-4000 \mathrm{~cm}^{-1}$, using $\mathrm{KBr}$ disk method.

The TPD was performed with a custom built setup equipped with a mass spectrometer (Omnistar ${ }^{\mathrm{TM}}$ Baltazar). In a typical experiment, the sample $(100 \mathrm{mg})$ was placed in an U-shaped quartz tube inside an electrical furnace and heated up to $900{ }^{\circ} \mathrm{C}$ at $10{ }^{\circ} \mathrm{C} \mathrm{min}{ }^{-1}$ in a constant Ar flow of $50 \mathrm{ml} \mathrm{min}^{-1}$. The desorbed $\mathrm{CO}_{2}(m / z=44)$ and $\mathrm{CO}(m / z=28)$ were monitored with the mass spectrometer during the heating process. Prior to desorption experiments, the samples were degassed for $1 \mathrm{~h}$ in Ar stream $\left(50 \mathrm{ml} \mathrm{min}^{-1}\right)$ at $120^{\circ} \mathrm{C}$.

XPS were acquired on an ESCALAB 250 electron spectrometer equipped with a $150 \mathrm{~W} \mathrm{Al} \mathrm{K} \alpha$ radiation as a primary excitation source. The binding energy scale was calibrated to $284.6 \mathrm{eV}$ for the main $\mathrm{C} 1 \mathrm{~s}$ peak.

In situ Diffuse Reflectance Infrared Fourier Transform Spectroscopy (DRIFTS) spectra were recorded in a Nicolet 6700 FTIR spectrometer equipped with a smart collector and a liquid $\mathrm{N}_{2}$ cooled MCT detector. The DRIFTS cell (Harrick) with ZnSe windows is fitted a heating cartridge that allows sample to be heated under atmospheric pressure. Before each experiment, $0.05 \mathrm{~g}$ finely ground sample was pretreated at $120^{\circ} \mathrm{C}$ for $1 \mathrm{~h}$ in a flow of $\mathrm{N}_{2}$ and then cooled down to room temperature. The background was collected before switching $\mathrm{N}_{2}$ with the reaction gas and the spectra were recorded with a resolution of $4 \mathrm{~cm}^{-1}$ and accumulating 32 scans after subtraction of the background.

\subsection{DFT calculation}

The molecular geometries of all compounds (acetaldehyde, CDC models and their adsorption complexes) were fully optimized using the DFT at the B3LYP/6-31G(d) computational level. All DFT calculations were performed with the Gaussian 09 program [14]. The original CDC model, graphene was composed of 4 benzene rings and hydrogen atoms that were used to saturate the carbon atoms with dangling bonds at the edge of graphene sheet, which is nearly the same size of model reported in previous work [15]. The oxygen functional groups considered in this work are carboxylic acid, anhydride and phenol groups. These functional groups were selected based on the characterization results that confirmed their presence and effects on adsorption. The acetaldehyde 
and different molecular models of simulated CDCs with various functional groups are depicted in Fig. 1.

To evaluate the interaction between acetaldehyde molecule and adsorbent surface, the adsorption energy $\left(\Delta E_{\text {ads }}\right)$ of the acetaldehyde molecule adsorption on CDCs (original or functionalized graphene) was calculated, which is defined as

$\Delta E_{\text {ads }}=E_{\text {adsorbent/acetaldehyde }}-E_{\text {adsorbent }}-E_{\text {acetaldehyde }}$

where $E_{\text {adsorbent/acetaldehyde }}$ denotes the total energies of acetaldehyde adsorbed on original or functionalized graphene. $E_{\text {adsorbent }}$ and $E_{\text {acetaldehyde }}$ are the total energies of original or functionalized graphene and an isolated acetaldehyde molecule, respectively.

\section{Results and discussion}

\subsection{Evaluation of dynamic adsorption performance}

The dynamic adsorption performance of acetaldehyde over original and modified CDCs was evaluated, as shown in Fig. 2.

It is apparent that the adsorption of acetaldehyde for samples is different and associates with the modified process using different oxidants which changes the physicochemical properties of CDCs. The adsorption performance of oxidized CDCs is much better than that of the original CDC, suggesting that the oxidation modification is effective for improving the acetaldehyde adsorption. On the basis of the breakthrough curve, the breakthrough capacity of
CDC-N is 3.5 times as high as that of original CDC, and the treatment with $\mathrm{H}_{2} \mathrm{O}_{2}$ or air enhances the capacity from 1.5 to 2.5 folds.

\subsection{Characterizations of the adsorbents}

\subsubsection{Porous structure characterization}

Fig. 3 shows the $\mathrm{N}_{2}$ adsorption-desorption isotherms and PSDs of the original and modified CDCs.

As shown in Fig. 3(a), the $\mathrm{N}_{2}$ adsorption is nearly completed at a low relative pressure $\left(P / P_{0}<0.05\right)$, and it shows a plateau over a wide range of relative pressure. Thus, all isotherms belong to Type I by IUPAC classification, indicating that these CDCs are typically microporous. As a result, the oxidation modification does not significantly change the pore structure of CDC. But the adsorption platform is different, which is attributed to the change of surface area. Treatment with $\mathrm{HNO}_{3}$ results in a slight decrease in the volume of adsorbed-desorbed $\mathrm{N}_{2}$. The decreases could be associated with the collapse of some pore walls to diminish the micropore volumes [16], or partial blockage of the micropore entrances by oxygen functional groups introduced by the $\mathrm{HNO}_{3}$ treatment [6]. Nevertheless, the loss of surface area is not as significant as that reported in literatures, in which the severe $\mathrm{HNO}_{3}$ oxidation conditions might even lead to complete destruction of the carbon texture [17]. Concerning the $\mathrm{CDC}-\mathrm{H}$, the amount of adsorbed $\mathrm{N}_{2}$ is quite close to the original $C D C$, suggesting that the loss of surface area on $\mathrm{CDC}-\mathrm{H}$ is negligible. On the other hand, air oxidization results in more adsorbed $\mathrm{N}_{2}$, which is attributed to the partial

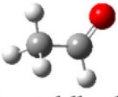

Acetaldhyde
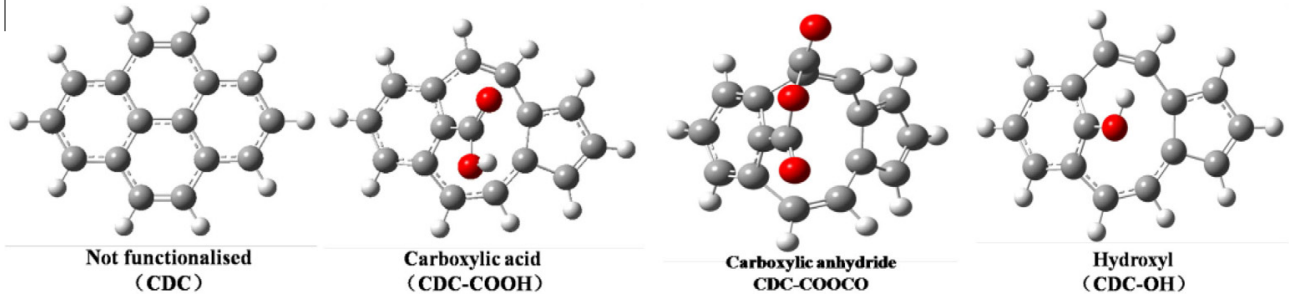

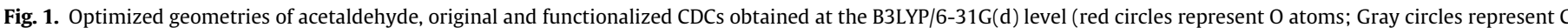
atoms; White circles represent $\mathrm{H}$ atoms). (For interpretation of the references to colour in this figure legend, the reader is referred to the web version of this article.)
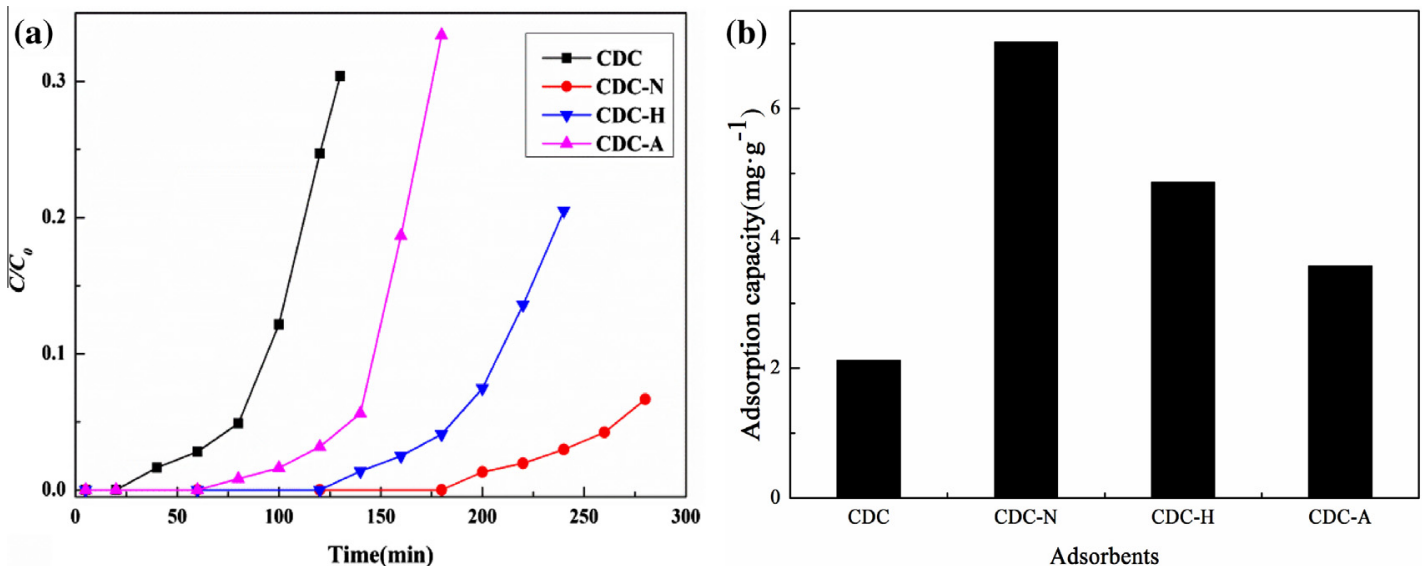

Fig. 2. Adsorption performance of acetaldehyde over different CDCs (a) breakthrough curves; (b) breakthrough adsorption capacity. 

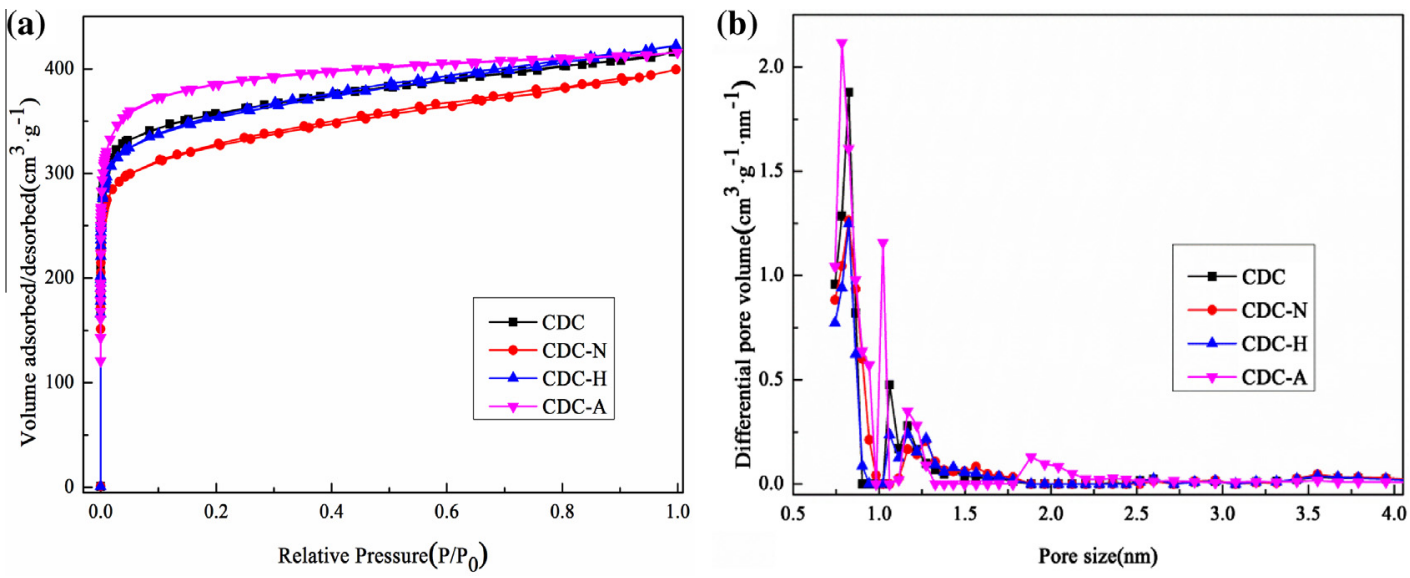

Fig. 3. (a) The $\mathrm{N}_{2}$ adsorption-desorption isotherms, and (b) PSDs of different CDCs.

Table 1

Pore characteristics of different CDCs.

\begin{tabular}{llllll}
\hline Sample & $\begin{array}{l}\text { SSA } \\
\left(\mathrm{m}^{2} \mathrm{~g}^{-1}\right)\end{array}$ & $\begin{array}{l}V_{\mathrm{t}}^{\mathrm{a}} \\
\left(\mathrm{cm}^{3} \mathrm{~g}^{-1}\right)\end{array}$ & $\begin{array}{l}V_{\text {mic }} \\
\left(\mathrm{cm}^{3} \mathrm{~g}^{-1}\right)\end{array}$ & $\begin{array}{l}V_{\text {meso }}{ }^{\mathrm{b}} \\
\left(\mathrm{cm}^{3} \mathrm{~g}^{-1}\right)\end{array}$ & $\begin{array}{l}D_{\mathrm{A}}{ }^{\mathrm{c}} \\
(\mathrm{nm})\end{array}$ \\
\hline CDC & 1473 & 0.644 & 0.477 & 0.167 & 1.85 \\
CDC-N & 1329 & 0.618 & 0.424 & 0.194 & 1.97 \\
CDC-H & 1440 & 0.654 & 0.473 & 0.181 & 1.92 \\
CDC-A & 1593 & 0.643 & 0.551 & 0.092 & 1.70 \\
\hline
\end{tabular}

a Total pore volume.

b Mesopore volume.

c Average pore width.

activation of carbon during the air oxidation process at high temperature $[18,19]$. This activation takes place by partial gasification of carbon to produce $\mathrm{CO}$ and $\mathrm{CO}_{2}$. As a result, more micropores are generated, which is shown in Fig. 3(b) and Table 1.

From Fig. 3(b), it can be seen that the oxidation does not change the PSDs significantly. All CDCs exhibit bimodal pore size distributions in the range of $0.7-1.5 \mathrm{~nm}$ fitting for acetaldehyde adsorption [5]. While it also can be seen that there is a slight decrease in differential pore volume for liquid phase oxidation CDCs and an increase for air oxidation CDC. Besides, there is a widening of pores after liquid phase oxidation, which is mainly due to the transition of micropores into mesopores after oxidation process.

As shown in Table 1, the pore structure does not change considerably, although it is clear that the $\mathrm{HNO}_{3}$ and air oxidation produce some slight variations in porosity, especially in the SSA and the $V_{\text {mic }}$ values which are important parameters for gas adsorption [20]. For liquid phase oxidation, the adsorption performance is enhanced even though the parameters are slightly decreased, especially for CDC-N. However, with the most developed porosity, CDC-A exhibits the lowest adsorption performance among the oxidized CDCs. The results imply that the differences among CDCs in surface chemistry may cause much more variations in the adsorption performance than the pore properties by oxidation modification.

\subsubsection{Surface chemistry characterization}

The surface chemistry of CDCs before and after oxidation was further investigated. The FT-IR spectra of the original and oxidized CDCs were presented in Fig. 4 . The spectra of these CDCs are rather similar in shape but vary in intensity. The broad band observed at the range of $3700-3000$ with a maximum at about $3440 \mathrm{~cm}^{-1}$ is assigned to the stretching vibration of $\mathrm{O}-\mathrm{H}$ functional groups because of the intermolecular and intramolecular hydrogen bonding of polymeric compounds such as alcohols, phenols, and carboxylic acids [21-23]. Small peaks at around $3000-2800 \mathrm{~cm}^{-1}$ denote the presence of the stretching $\mathrm{C}-\mathrm{H}$ in aliphatic hydrocarbons $[24,25]$. In addition, there is a band at $1625 \mathrm{~cm}^{-1}$ indicating the overlapping of the $\mathrm{v}(\mathrm{C}=\mathrm{C})$ stretching vibration mode of the aromatic ring of the carbon with the $\mathrm{v}(\mathrm{C}=\mathrm{O})$ absorption bands of carboxylic, ester, lactone, and carbonyl groups [26,27]. As for the band at $1455 \mathrm{~cm}^{-1}$, it can be attributed to either an $\mathrm{O}-\mathrm{H}$ deformation vibration in carboxyl groups or $\mathrm{C}-\mathrm{H}$ bending vibrations in $\mathrm{CH}_{2}$ or $\mathrm{CH}_{3}$ groups $[28,29]$. The band at $1384 \mathrm{~cm}^{-1}$ indicates the $\mathrm{C}=\mathrm{O}$ belonged to the carbonate groups [25,30,31]. Moreover, some small weak peaks in the region of $1300-1000 \mathrm{~cm}^{-1}$ consist of a series of overlapping absorptions that can be ascribed to $\mathrm{C}-\mathrm{O}$ bands in various chemical surroundings, where out of plane bending of $\mathrm{O}-\mathrm{H}$ in ring ethers and primary $\mathrm{C}-\mathrm{OH}$ occur $[10,32]$. The band at around $1270 \mathrm{~cm}^{-1}$ is the $\mathrm{C}-\mathrm{O}$ stretching in carboxylic groups, anhydrides, phenols, ethers and lactones [33] or $\mathrm{C}-\mathrm{O}-\mathrm{C}$ stretching vibration in lactones and ethers [34,35]. And the bands at 1120 and $1050 \mathrm{~cm}^{-1}$ are assigned to phenolic $\mathrm{O}-\mathrm{H}$ bending [36-38]. Bands below $1000 \mathrm{~cm}^{-1}$ are characteristic of out-of-plane deformation vibrations of $\mathrm{C}-\mathrm{H}$ groups in aromatic structures [35,39-41].

It can be noted from Fig. 4 that the surfaces of the modified CDCs contain the same oxygen functional groups mainly including carboxylic acids, carboxylic anhydrides, phenols and lactones as the original CDC does, while we could not determine the amount of a specific group because the bands are overlapped. However,

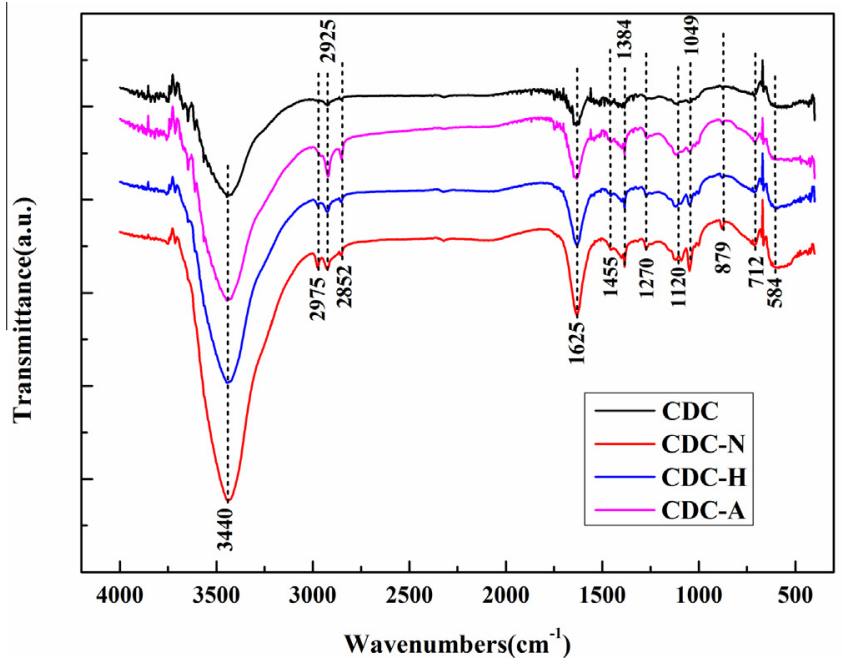

Fig. 4. FT-IR spectra of CDCs. 
the intensity of the bands is elevated with the oxidization treatments with the order of CDC-N > CDC-H > CDC-A > CDC, which indicates that more oxygen functional groups have been introduced on the CDC surface after oxidation. Besides, this trend is consistent with that of adsorption performance, implying that the increased adsorption capacity of oxidized CDCs can be attributed to the increase of oxygen functional groups. These results are in agreement with previous researches $[42,43]$ which pointed out the oxygen functional groups appeared to play an important role on adsorption of acetaldehyde even it remained unclear what the active sites of adsorption are. Similar chemical behavior of the adsorbent surface and the adsorbate can enhance the interaction between them [44]. Thus, the oxidized CDCs with more polar surface related to higher oxygen functional groups can allow the enhancement of adsorption tendency for polar acetaldehyde compared with original CDC.

To find out which type of oxygen functional group is responsible for this enhancement, the TPD of original and oxidized CDCs was carried out, as shown in Fig. 5. As expected, oxidation treatments increase the amount of oxygen functional groups, which is evidenced by the increase of the $\mathrm{CO}_{2}$ and $\mathrm{CO}$ peaks. The $\mathrm{CO}_{2}$ spectra are quite distinct: the liquid phase treatments increase the $\mathrm{CO}_{2}$ evolution at low temperatures (below $400{ }^{\circ} \mathrm{C}$ ), which is due to the decomposition of carboxylic acid functional groups with different acid strengths or located on energetically different carbon sites $[9,10,45,46]$. However, the oxidation in gas phase induces high $\mathrm{CO}_{2}$ evolution at higher temperatures, which results from the decomposition of carboxylic anhydrides and lactones [47]. The tails in $\mathrm{CDC}-\mathrm{N}$ and $\mathrm{CDC}-\mathrm{H}$ after 400 up to $800^{\circ} \mathrm{C}$ also suggest the presence of anhydrides and lactones in them. Besides, the gas phase treatment gives much more $\mathrm{CO}$ than the liquid phase treatments, but in all cases the CO-TPD profiles show one wide peak at around $700{ }^{\circ} \mathrm{C}$ which may originate from phenols. The appearance of small $\mathrm{CO}$ desorption peaks at low temperatures may be due to the thermal decomposition of carbonyl groups in $\alpha$-substituted ketones and aldehydes $[45,48]$. In addition, compared with the original $\mathrm{CDC}$, the peaks of oxidized $\mathrm{CDC}$ are located at higher temperature, which indicates that these groups are more stable on oxidized CDC.

In addition, the amounts of released $\mathrm{CO}_{2}$ and $\mathrm{CO}$ were calculated by integration of the areas under the TPD peaks and their ratios were given in Table 2. The listed values were normalized by the area of original CDC arbitrarily set to 1.0 . This ratio increases significantly after liquid phase treatments, and increases slightly after gas phase treatment. The results are consistent with a significant increase in $\mathrm{CO}_{2}$-evolving groups like carboxylic acid after liquid phase treatments, whereas gas phase oxidation increases more phenol surface groups, which release mostly in CO. Moreover, considering the acidic
Table 2

Amounts of $\mathrm{CO}_{2}$ and $\mathrm{CO}$ evolved after heating up to $900{ }^{\circ} \mathrm{C}$ in $\mathrm{Ar}$ flow.

\begin{tabular}{llllr}
\hline Sample & $\mathrm{CO}_{2}$ & $\mathrm{CO}$ & $\mathrm{CO}_{2} / \mathrm{CO}$ & \multicolumn{1}{c}{$\mathrm{O}_{\mathrm{T}}$} \\
\hline $\mathrm{CDC}$ & 1.0 & 1.0 & 1.00 & 3.0 \\
$\mathrm{CDC}-\mathrm{N}$ & 4.0 & 2.1 & 1.90 & 10.1 \\
$\mathrm{CDC}-\mathrm{H}$ & 3.2 & 1.7 & 1.88 & 8.1 \\
$\mathrm{CDC}-\mathrm{A}$ & 2.7 & 2.4 & 1.12 & 7.7 \\
\hline
\end{tabular}

nature of the $\mathrm{CO}_{2}$ releasing groups and the relatively neutral and/or basic character of $\mathrm{CO}$ releasing groups, $\mathrm{CDC}-\mathrm{N}$ exhibits the highest acidity, followed by CDC-H, CDC-A and CDC, which is also consistent with the trend of adsorption performance. These acidic oxygen functional groups improve the hydrophilic of carbon surfaces $[49,50]$ and the polar compound of acetaldehyde is apt to be adsorbed by a hydrophilic surface, which leads to the enhancement of adsorption performance.

From the amounts of $\mathrm{CO}_{2}$ and $\mathrm{CO}$ evolved, the total oxygen content, $\mathrm{O}_{\mathrm{T}}$, was also obtained. It can be seen that the $\mathrm{HNO}_{3}$ treatment results in a significant increase of oxygen functional groups and the $\mathrm{O}_{\mathrm{T}}$ is about 3.5 times higher as that of original CDC. $\mathrm{H}_{2} \mathrm{O}_{2}$ treatment also leads to an increase of $\mathrm{O}_{\mathrm{T}}$ which is around 2.7 higher as that of CDC. Treatment with air results in relatively mild modification, with an increase of only about 2.5 times. Thus, the promotion effect of various oxidation treatments on the introduction of oxygen functional groups to $\mathrm{CDC}$ surface follows the order of $\mathrm{HNO}_{3}>\mathrm{H}_{2} \mathrm{O}_{2}>$ air, which is consistent with FT-IR results and adsorption performance. Therefore, it confirms that the oxygen functional groups play a key role in affecting the acetaldehyde adsorption after oxidation.

Moreover, the TPD profiles of CDC-N and CDC-H are similar, especially there is almost no difference in the shape and intensity of $\mathrm{CO}$ evolving profiles. $\mathrm{HNO}_{3}$ treatment produces $\mathrm{CDC}$ with large amounts of surface acidic groups, mainly carboxylic acids and anhydrides. Whereas $\mathrm{H}_{2} \mathrm{O}_{2}$ treatment produces less these groups, which results in the main difference of the $\mathrm{CO}_{2}$ evolving profiles between them. However, the significant variations in adsorption performance between the two samples are observed, which suggests that the effect of phenol groups on the adsorption is limited while the carboxylic acids and anhydrides play an important role. This is also the reason why the more the acidic functional groups on the CDC surfaces are, the higher the amount of acetaldehyde adsorbed on the corresponding CDC is.

Furthermore, XPS analysis was used for evaluating the changes in the chemical bonding states and concentrations of surface functional groups formed by oxidation modification. The XPS spectra of CDCs usually show two distinct peaks from carbon (C1s) and oxygen (01s). The ratio $\mathrm{C} 1 \mathrm{~s} / 01 \mathrm{~s}$ represents a measure of describing the
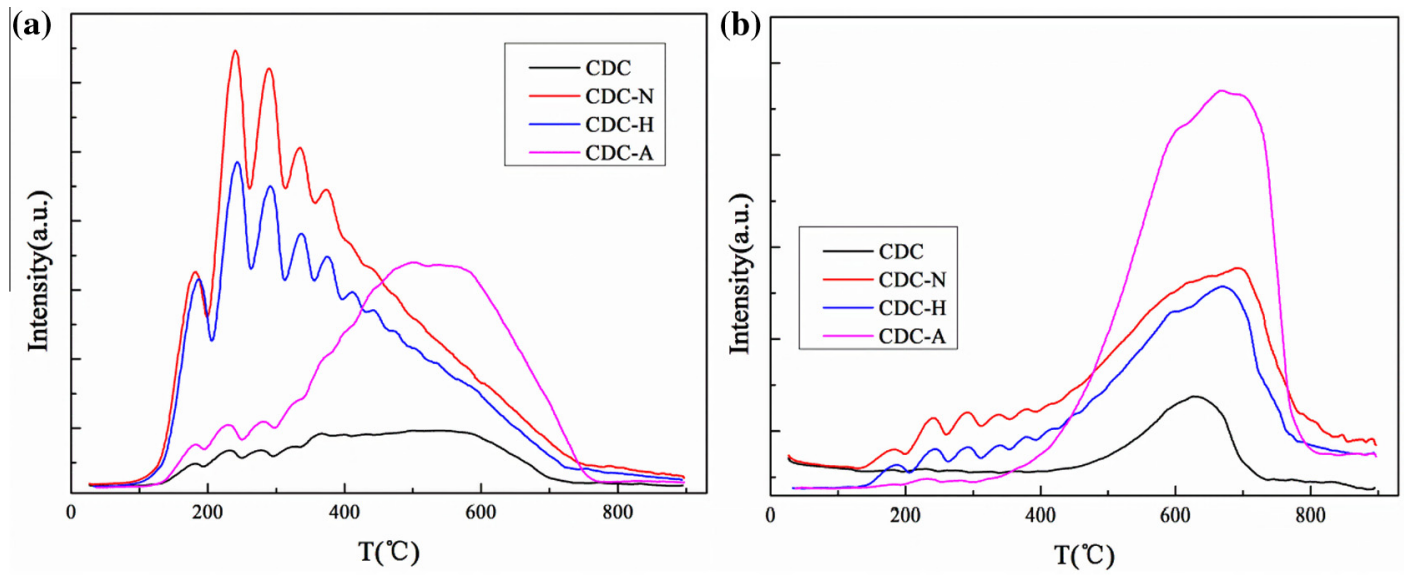

Fig. 5. TPD profiles of different CDCs: (a) $\mathrm{CO}_{2}$ evolution; (b) $\mathrm{CO}$ evolution. 
Table 3

Relative contents of functional groups in C1s from XPS spectra and distribution of oxygen groups on CDCs.

\begin{tabular}{|c|c|c|c|c|c|c|c|c|c|}
\hline \multirow[t]{2}{*}{ Sample } & \multicolumn{5}{|c|}{ C 1s (\%) } & \multirow[t]{2}{*}{$\mathrm{O}_{\mathrm{X}}^{\mathrm{a}}$ (at.\%) } & \multirow[t]{2}{*}{$\mathrm{C} / \mathrm{O}_{\mathrm{X}}$} & \multirow[t]{2}{*}{$\mathrm{O}_{\mathrm{X}} / \mathrm{O}_{\mathrm{T}}$} & \multirow[t]{2}{*}{ N.O. } \\
\hline & Peak 1 & Peak 2 & Peak 3 & Peak 4 & Peak 5 & & & & \\
\hline $\mathrm{CDC}$ & 58.34 & 24.23 & 8.66 & 4.68 & 4.09 & 10.85 & 6.82 & 3.62 & 1 \\
\hline CDC-N & 56.76 & 25.06 & 9.35 & 5.24 & 3.59 & 13.67 & 5.37 & 1.34 & 0.37 \\
\hline CDC-H & 57.02 & 25.68 & 8.85 & 4.95 & 4.95 & 13.24 & 5.47 & 1.63 & 0.45 \\
\hline CDC-A & 54.50 & 26.54 & 10.09 & 4.78 & 4.78 & 11.16 & 6.56 & 1.45 & 0.40 \\
\hline
\end{tabular}

a The oxygen content from XPS measurement.

b Normalized oxygen group distribution as N.O. $=\frac{\left[\mathrm{O}_{\mathrm{X}} / \mathrm{O}_{\mathrm{T}}\right]_{\mathrm{CDC} . \mathrm{CDC}-\mathrm{N} \cdot \mathrm{CDC}-\mathrm{H} . \mathrm{CDC}-\mathrm{A}}}{\left[\mathrm{O}_{\mathrm{X}} / \mathrm{O}_{\mathrm{T}}\right]_{\mathrm{CDC}}}$.

degree of oxidation. It is noticed that the ratio (Table 3) decreases when the CDC is oxidized, which indicates that more oxygen functional groups have been introduced on CDC surface after oxidation. This agrees well with the FT-IR and TPD results that much more $\mathrm{CO}_{2}$ and $\mathrm{CO}$ are desorbed after oxidation. Another difference among the $\mathrm{CDCs}$ is that the atomic percent of oxygen on the surface increases in the order of CDC $<$ CDC-A $<$ CDC-H $<$ CDC-N. This order is consistent with that of adsorption performance, which corroborates the view that the oxygen functional groups on the $\mathrm{CDC}$ surface improve the adsorption performance for acetaldehyde.

For the sake of a better understanding of the surface chemistry change by the oxidation, the $\mathrm{C} 1 \mathrm{~s}$ signals were deconvoluted. Although modern XPS instruments provide a good resolution even for 01s spectra, it is generally known that the measurement of the C1s signals is more convenient [51]. The C1s spectra are resolved into five individual component peaks, as illustrated in Fig. 6, namely the following [52,53]: peak $1(284.6 \mathrm{eV})$, graphitized carbon $(\mathrm{C}-\mathrm{C})$; peak $2(285.6 \mathrm{eV})$, carbon in phenol, alcohol, or ether groups(C-O-); peak $3(287 \mathrm{eV})$, carbon in carbonyl or quinone groups $(C=0)$; peak $4(288.5 \mathrm{eV})$, carbon in carboxyl or ester (anhydrides) groups $(\mathrm{O}-\mathrm{C}=\mathrm{O})$; and peak $5(290.2 \mathrm{eV})$, carbon in carbonate groups and/or adsorbed $\mathrm{CO}$ and $\mathrm{CO}_{2}$. Through the same fitting method, the relative amounts of carbon atoms in different functional groups calculated by the area of bonding energy peaks are summarized in Table 3.

After oxidation modification, the relative amount of the graphitized carbon (peak 1) decreases and that of the carbon bonded to oxygen functional groups (peaks 2-5) increases. For the CDC modified with air, this increase results primarily from an increase in peak 2 (phenolic, alcohol, or ether group) and 3 (carbonyl or quinine groups). However, for the CDC modified with $\mathrm{HNO}_{3}$ and $\mathrm{H}_{2} \mathrm{O}_{2}$, the increase mostly originates from an increase in peak 4 assigned to carboxyl or anhydrides groups. Interestingly, the $\mathrm{HNO}_{3}$

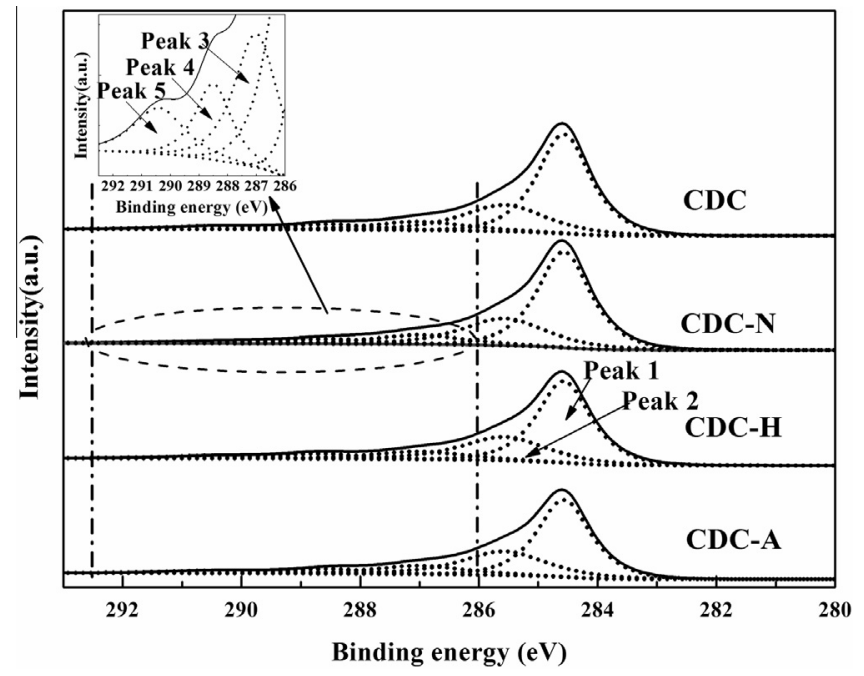

Fig. 6. Curve-fitted C1s of XPS spectra for different CDCs. oxidation reduces the content of $\mathrm{CO}_{3}$ (peaks 5) from $4.09 \%$ for $\mathrm{CDC}$ to 3.59 \% for CDC-N, probably due to the removal of carbonate existing in $\mathrm{CDC}$ in the $\mathrm{HNO}_{3}$ oxidation treatment [54]. Overall, the XPS results are in line with the TPD results.

In addition, given that the XPS method only measures the groups on the uppermost layers of CDC whereas TPD can be considered as a bulk analysis method, the comparison of the two results can give an idea about the distribution of oxygen groups on samples [12,55]. In Table 3, the ratio of the total oxygen content of XPS to TPD is taken as a measure of the distribution of oxygen (i.e., the lower ratio means formation of more oxygen groups in interior surface). The last column, normalized oxygen group distribution (N.O.) is obtained after normalizing the $\mathrm{O}_{\mathrm{X}} / \mathrm{O}_{\mathrm{T}}$ ratio of all samples by that of original CDC. The data given in Table 3 indicates that the oxygen groups of original CDC are essentially concentrated on external surface, while the oxidized CDCs have similar distribution of oxygen groups mainly in internal surface. However, compared with the other two treatments, the formation of oxygen groups in internal surfaces of CDC-N is pronounced. This could be linked to a higher erosion of the surface that facilitates the access of $\mathrm{HNO}_{3}$ [23], which also results in its slight loss of porosity. In addition, the adsorption performance depends on the accessibility of adsorbate molecules to the interior surface of the adsorbent [56]. As a result, the massive incorporation of oxygen functional groups in the internal surface of CDC-N compensates the loss of porosity, increasing the adsorption capacity of acetaldehyde.

\subsection{Calculation results}

The optimized molecular geometries of acetaldehyde adsorption over original and functionalized graphene surfaces and the adsorption energies are shown in Table 4. From Table 4, the calculated adsorption energies of acetaldehyde on the original and functionalized graphene are negative, which indicates that these adsorbed states are energetically favorable. The lowest adsorption energy is obtained between acetaldehyde molecule and the original graphene, which is the reason of the worst adsorption performance on original CDC. In the case of acetaldehyde adsorption on functionalized graphenes, calculations show that the adsorption energies are much higher than those of original graphene, which confirms that the acetaldehyde adsorption of CDC is significantly increased by oxidization treatment. In addition, surfaces functionalized with carboxylic acid or anhydride groups exhibit high adsorption energies, suggesting that the acetaldehyde molecule tends to approach much more conveniently towards these acidic groups and the interactions between them are strong. The CDC-N has the highest concentration of carboxylic acid and anhydrides, resulting in the highest adsorption capacity of acetaldehyde. Also, the phenols functionalized graphene displays stronger interaction with acetaldehyde molecule than original graphene even though the improvement is very limited. Therefore, the CDC-A with the high concentration of phenol groups and a certain amount of anhydride groups also exhibits better adsorption performance than original CDC. 
Table 4

DFT optimized geometries of the acetaldehyde interaction with the functional groups on CDC surface and the corresponding adsorption energies.
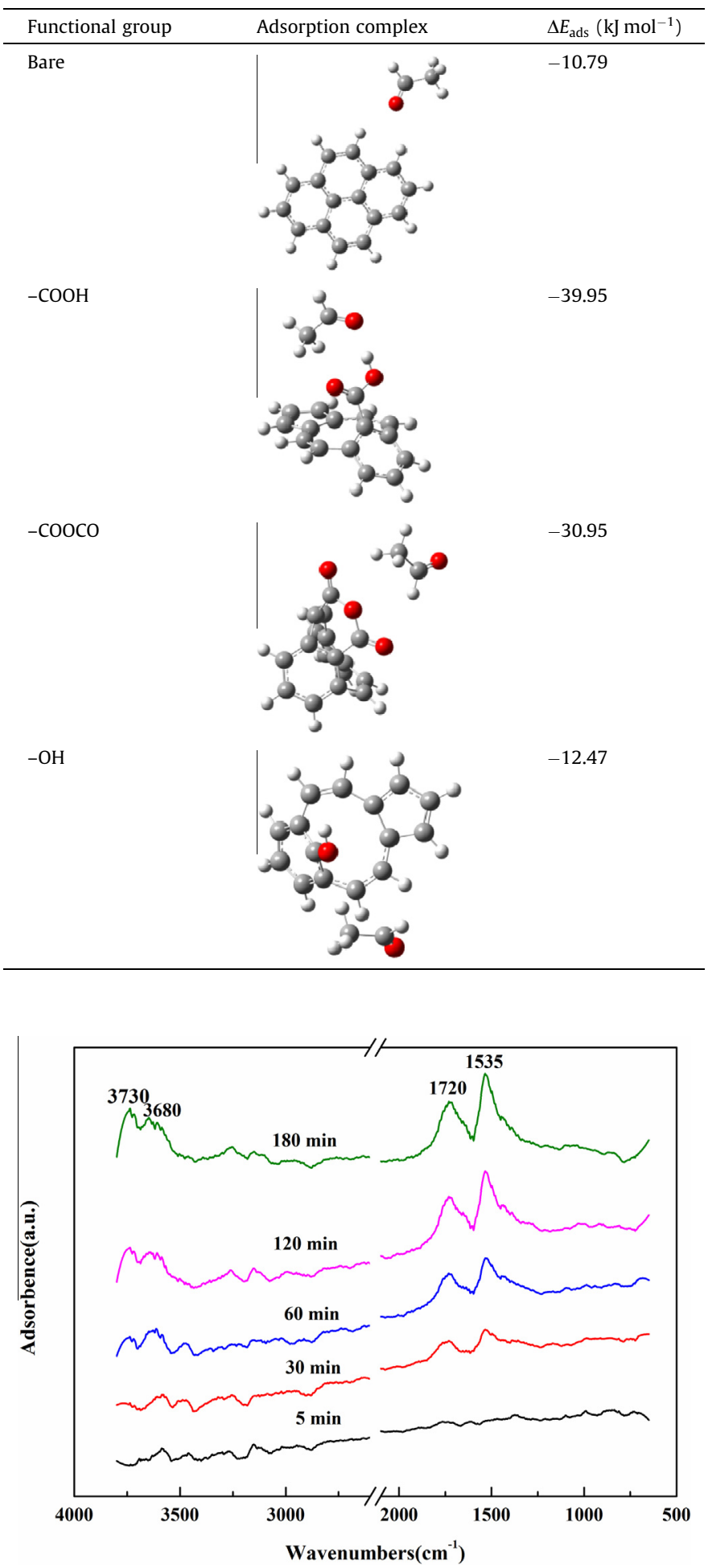

Fig. 7. In situ DRIFTS of acetaldehyde adsorption on CDC-N

Generally, the attraction between adsorbate and adsorbent arises from some of forces listed below: van der Waals forces (4$10 \mathrm{~kJ} / \mathrm{mol}$ ), hydrophobic bond forces $(5 \mathrm{~kJ} / \mathrm{mol})$, hydrogen bond forces $(2-40 \mathrm{~kJ} / \mathrm{mol})$, coordination exchange $(40 \mathrm{~kJ} / \mathrm{mol})$, dipole bond forces $(2-29 \mathrm{~kJ} / \mathrm{mol})$, and chemical bond forces $(>60 \mathrm{~kJ} / \mathrm{mol})$ $[57,58]$. In this study, the adsorption energies ranged from -10.79 to $-39.95 \mathrm{~kJ} / \mathrm{mol}$. This suggested that the above-mentioned forces were involved for the adsorption of acetaldehyde except coordination and chemical bond forces. Also, if hydrogen bonding is present, it is the main force as compared with van der Waals, hydrophobic bond, and dipole bond forces [59]. Thus, we deduced that hydrogen bonding interaction dominated the process of acetaldehyde adsorption onto oxidized CDCs. The results are in agreement with previous researches $[42,43]$ which pointed out the oxygen functional groups enhance adsorption via hydrogen bonding and dipole interactions.

To obtain the surface species formed during adsorption of acetaldehyde on the surface of modified CDC, in situ DRFIT spectra of the CDC-N interaction with acetaldehyde were recorded, and the representative time resolution spectra are presented in Fig. 7. It can be seen that four distinct bands at $3730,3680,1720$ and $1535 \mathrm{~cm}^{-1}$ appear and the intensity increases as the reaction proceeding. The $1720 \mathrm{~cm}^{-1}$ can be ascribed to $\mathrm{v}(\mathrm{C}=0)$ of acetaldehyde in the gas phase [60]. While the very strong band observed at $1550 \mathrm{~cm}^{-1}$ is assigned to $\mathrm{C}=\mathrm{O}$ stretching vibrations of adsorbed acetaldehyde because of hydrogen bonding which shifts the absorption to lower wavenumber [61]. The observation indicates that the adsorbed acetaldehyde is molecular. In addition, the bands at 3730 and $3680 \mathrm{~cm}^{-1}$ also show that acetaldehyde may be adsorb through hydrogen bonding with oxygen functional groups of the adsorbent [60]. Therefore, hydrogen bonding interaction dominates the process of acetaldehyde adsorption onto oxidized CDCs as predicted by the DFT calculation.

\section{Conclusions}

A combined fixed-bed adsorption and DFT calculation study was carried out to clarify the effect of oxidation modification on the properties and adsorption performance of CDC for acetaldehyde. It was observed that the oxidation modification could significantly enhance the adsorption performance of CDC. After oxidation, the effects of oxygen functional group on acetaldehyde adsorption are much stronger than that of pore properties. The CDC oxidized by $\mathrm{HNO}_{3}$ exhibits the highest adsorption performance due to its largest number of acidic oxygen-containing groups like carboxylic acids and anhydrides. These groups are mainly in the internal surface and create favorable interactions with the acetaldehyde molecule. In agreement with the experimental results, the DFT calculations show that the acidic oxygen-containing groups display strong hydrogen bonding interactions with acetaldehyde molecule, leading to the enhanced adsorption performance.

\section{Acknowledgements}

The authors would like to thank the National High Technology Research and Development Program of China (No. 2012AA 062702), National Natural Science Foundation (No. 21177006) and the National Commonweal Project of the Ministry of Environmental Protection (No. 201409080).

\section{References}

[1] J.L. Perry, P.L. Belcher, S.A. Johnson, Status of the International Space Station(ISS) Trace Contaminant Control System, SAE Int. J. Aerospace 4 (2011) 48-54.

[2] A. Macatangay, S. Townsend, K. Prokhorov, Maintaining and monitoring the habitable environment of the international space station, SAE Int. J. Aerospace 1 (2009) 420-428.

[3] T. Aguilera, J. Perry, Root cause assessment of pressure drop rise of a packed bed of lithium hydroxide in the international space station trace contaminant control system, SAE Int. J. Aerospace 4 (2011) 291-298.

[4] A. Honne, H. Schumann-Olsen, K. Kaspersen, S. Clausen, H. Mosebach, D. Kampf, T. Stuffler, W. Supper, G. Tan, ANITA air monitoring on the international space station Part 2: Air analyses, SAE Int. J. Aerospace 1 (2009) 178-192. 
[5] H.Y. Wang, T.L. Zhu, X. Fan, H.B. Na, Adsorption and desorption of small molecule volatile organic compounds over carbide-derived carbon, Carbon 67 (2014) 712-720.

[6] S.A. Carabineiro, T. ThavornAmornsri, M.F. Pereira, J.L. Figueiredo, Adsorption of ciprofloxacin on surface-modified carbon materials, Water Res. 45 (2011) 4583-4591.

[7] A. Derylo-Marczewska, B. Buczek, A. Swiatkowski, Effect of oxygen surface groups on adsorption of benzene derivatives from aqueous solutions onto active carbon samples, Appl. Surf. Sci. 257 (2011) 9466-9472.

[8] C.C. Huang, H.S. Li, C.H. Chen, Effect of surface acidic oxides of activated carbon on adsorption of ammonia, J. Hazard. Mater. 159 (2008) 523-527.

[9] J.L. Figueiredo, M.F.R. Pereira, M.M.A. Freitas, J.J.M. Órfão, Modification of the surface chemistry of activated carbons, Carbon 37 (1999) 1379-1389.

[10] P.M. Alvarez, J.F. GarcíaAraya, F.J. Beltrán, F.J. Masa, F. Medina, Ozonation of activated carbons: effect on the adsorption of selected phenolic compounds from aqueous solutions, J. Colloid Interface Sci. 283 (2005) 503-512.

[11] C. Moreno-Castilla, M.A. Ferro-Garcia, J.P. Joly, I. Bautista-Toledo, F. CarrascoMarin, J. Rivera-Utrilla, Activated carbon surface modifications by nitric acid, hydrogen peroxide, and ammonium peroxydisulfate treatments, Langmuir 11 (1995) 4386-4392.

[12] W.M.A.W. Daud, A.H. Houshamnd, Textural characteristics, surface chemistry and oxidation of activated carbon, J. Nat. Gas Chem. 19 (2010) 267-279.

[13] P. Vassileva, P. Tzvetkova, R. Nickolov, Removal of ammonium ions from aqueous solutions with coal-based activated carbons modified by oxidation, Fuel 88 (2008) 387-390.

[14] M.J. Frisch, G.W. Trucks, H.B. Schlegel, G.E. Scuseria, M.A. Robb, J.R. Cheeseman, G. Scalmani, V. Barone, B. Mennucci, G.A. Petersson, H. Nakatsuji, M. Caricato, X. Li, H.P. Hratchian, A.F. Izmaylov, J. Bloino, G. Zheng, J.L. Sonnenberg, M. Hada, M. Ehara, K. Toyota, R. Fukuda, J. Hasegawa, M. Ishida, T. Nakajima, Y. Honda, O. Kitao, H. Nakai, T. Vreven, J.A. Montgomery Jr., J.E. Peralta, F. Ogliaro, M. Bearpark, J.J. Heyd, E. Brothers, K.N. Kudin, V.N. Staroverov, R. Kobayashi, J. Normand, K. Raghavachari, A. Rendell, J.C. Burant, S.S. Iyengar, J. Tomasi, M. Cossi, N. Rega, J.M. Millam, M. Klene, J.E. Knox, J.B. Cross, V. Bakken, C. Adamo, J. Jaramillo, R. Gomperts, R.E. Stratmann, O. Yazyev, A.J. Austin, R. Cammi, C. Pomelli, J. Ochterski, R.L. Martin, K. Morokuma, V.G. Zakrzewski, G.A. Voth, P. Salvador, J.J. Dannenberg, S. Dapprich, A.D. Daniels, O. Farkas, J.B. Foresman, J.V. Ortiz, J. Cioslowski, D.J. Fox, Gaussian 09 (Revision A.02), Gaussian Inc, Wallingford, CT, 2009.

[15] X. Huang, W. Chu, W. Sun, C.F. Jiang, Y.Y. Feng, Y. Xue, Investigation of oxygencontaining group promotion effect on $\mathrm{CO}_{2}$-coal interaction by density functional theory, Appl. Surf. Sci. 299 (2014) 162-169.

[16] M.F.R. Pereira, S.F. Soares, J.J.M. Órfão, J.L. Figueiredo, Adsorption of dyes on activated carbons: influence of surface chemical groups, Carbon 41 (2003) $811-821$.

[17] C.O. Ania, J.B. Parra, J.J. Pis, Influence of oxygen-containing functional groups on active carbon adsorption of selected organic compounds, Fuel Process. Technol. 79 (2002) 265-271.

[18] N. Mahata, M.F.R. Pereira, F. Suárez-García, A. Martínez-Alonso, J.M.D. Tascón, J.L. Figueiredo, Tuning of texture and surface chemistry of carbon xerogels, J. Colloid Interface Sci. 324 (2008) 150-155.

[19] M. Franz, H.A. Arafat, N.G. Pinto, Effect of chemical surface heterogeneity on the adsorption mechanism of dissolved aromatics on activated carbon, Carbon 38 (2000) 1807-1819.

[20] J.H. Tsai, H.M. Chiang, G.Y. Huang, H.L. Chiang, Adsorption characteristics of acetone, chloroform and acetonitrile on sludge-derived adsorbent, commercial granular activated carbon and activated carbon fibers, J. Hazard. Mater. 154 (2008) 1183-1191.

[21] W.M. Davis, C.L. Erickson, C.T. Johnston, J.J. Delfino, J.E. Porter, Quantitative Fourier transform infrared spectroscopic investigation of humic substance functional group composition, Chemosphere 38 (1999) 2913-2928.

[22] Q.L. Fang, B.L. Chen, Adsorption of perchlorate onto raw and oxidized carbon nanotubes in aqueous solution, Carbon 50 (2012) 2209-2219.

[23] H. ShamsiJazeyi, T. Kaghazchi, Investigation of nitric acid treatment of activated carbon for enhanced aqueous mercury removal, J. Ind. Eng. Chem. 16 (2010) 852-858.

[24] A.A. El-Hendawy, Influence of $\mathrm{HNO}_{3}$ oxidation on the structure and adsorptive properties of corncob-based activated carbon, Carbon 41 (2003) 713-722.

[25] W.Z. Shen, H. Wang, Y.H. Liu, Q.J. Guo, Y.L. Zhang, Oxidization activated carbon fiber through nitrocellulose combustion, Colloids Surf. A 308 (2007) 20-24.

[26] J. Xu, R.J. Zhang, P. Chen, S.H. Ge, Effects of adding ethanol to $\mathrm{KOH}$ electrolyte on electrochemical performance of titanium carbide-derived carbon, J. Power Sources 246 (2014) 132-140.

[27] T.A. Kurniawan, W.H. Lo, M.E. Sillanpää, Treatment of contaminated water laden with 4-chlorophenol using coconut shell waste-based activated carbon modified with chemical agents, Sep. Sci. Technol. 46 (2011) 460-472.

[28] M. Seredych, E. Deliyanni, J. BandoszTeresa, Role of microporosity and surface chemistry in adsorption of 4,6-dimethyldibenzothiophene on polymerderived activated carbons, Fuel 89 (2010) 1499-1507.

[29] V. Boonamnuayvitaya, S. Sae-ung, W. Tanthapanichakoon, Preparation of activated carbons from coffee residue for the adsorption of formaldehyde, Sep. Purif. Technol. 42 (2005) 159-168.

[30] S. Biniak, G. Szymanski, J. Siedlewski, A. Swiatkowski, The characterization of activated carbons with oxygen and nitrogen surface groups, Carbon 35 (1997) $1799-1810$
[31] W.Z. Shen, H. Wang, R.G. Guan, Z.J. Li, Surface modification of activated carbon fiber and its adsorption for vitamin B1 and folic acid, Colloids Surf. A 33 (2008) 263-267.

[32] L. Stobinski, B. Lesiak, L. Kövér, J. Tóth, S. Biniak, G. Trykowski, J. Judek, Multiwall carbon nanotubes purification and oxidation by nitric acid studied by the FTIR and electron spectroscopy methods, J. Alloys Compd. 501 (2010) 77-84.

[33] A.M.T. Silva, B.F. Machado, J.L. Figueiredo, J.L. Faria, Controlling the surface chemistry of carbon xerogels using $\mathrm{HNO}_{3}$-hydrothermal oxidation, Carbon 47 (2009) 1670-1679.

[34] S. Shin, J. Jang, S.H. Yoon, I. Mochida, A study on the effect of heat treatment on functional groups of pitch based activated carbon fiber using FTIR, Carbon 35 (1997) 1739-1743.

[35] A.A. El-Hendawy, A.J. Alexander, R.J. Andrews, G.G. Forrest, Effects of activation schemes on porous, surface and thermal properties of activated carbons prepared from cotton stalks, J. Anal. Appl. Pyrolysis 82 (2008) 272-278.

[36] G.Z. Kyzas, N.K. Lazaridis, E.A. Deliyanni, Oxidation time effect of activated carbons for drug adsorption, Chem. Eng. J. 234 (2013) 491-499.

[37] P.A.M. Mourão, C. Laginhas, F. Custódio, J.M.V. Nabais, P.J.M. Carrott, M.M.L. Ribeiro Carrott, Influence of oxidation process on the adsorption capacity of activated carbons from lignocellulosic precursors, Fuel Process. Technol. 92 (2011) 241-246.

[38] C.Y. Lu, F.S. Su, S. Hu, Surface modification of carbon nanotubes for enhancing BTEX adsorption from aqueous solutions, Appl. Surf. Sci. 254 (2008) 7035-7041.

[39] J. Przepiórski, M. Skrodzewicz, A.W. Morawski, High temperature ammonia treatment of activated carbon for enhancement of $\mathrm{CO}_{2}$ adsorption, Appl. Surf. Sci. 225 (2004) 235-242.

[40] B.S. Girgis, E. Smith, M.M. Louis, A.A. El-Hendawy, Pilot production of activated carbon from cotton stalks using $\mathrm{H}_{3} \mathrm{PO}_{4}$, J. Anal. Appl. Pyrolysis 86 (2009) 180-184.

[41] A.M. Puziy, O.I. Poddubnaya, A. Martínez-Alonso, F. Suárez-García, J.M.D. Tascón, Surface chemistry of phosphorus-containing carbons of lignocellulosic origin, Carbon 43 (2005) 2857-2868.

[42] Y. ElSayed, T.J. Bandosz, A study of acetaldehyde adsorption on activated carbons, J. Colloid Interface Sci. 242 (2001) 44-51.

[43] E.D. Dimotakis, M.P. Cal, J. Economy, M.J. Rood, S.M. Larson, Chemically treated activated carbon cloths for removal of volatile organic carbons from gas streams: evidence for enhanced physical adsorption, Environ. Sci. Technol. 29 (1995) 1876-1880.

[44] T. García, R. Murillo, D. Cazorla-Amorós, A.M. Mastral, A. Linares-Solano, Role of the activated carbon surface chemistry in the adsorption of phenanthrene, Carbon 42 (2004) 1683-1689.

[45] J.L. Figueiredo, M.F.R. Pereira, M.M.A. Freitas, J.J.M. Órfão, Characterization of active sites on carbon catalysts, Ind. Eng. Chem. Res. 46 (2007) 4110-4115.

[46] N. Li, X.L. Ma, Q.Z. Zhao, K. Kim, Y.S. Chen, C.S. Song, Maximizing the number of oxygen-containing functional groups on activated carbon by using ammonium persulfate and improving the temperature-programmed desorption characterization of carbon surface chemistry, Carbon 49 (2011) 5002-5013.

[47] J.L. Figueiredo, M.F.R. Pereira, The role of surface chemistry in catalysis with carbons, Catal. Today 150 (2010) 2-7.

[48] C. Moreno-Castilla, F. Carrasco-Marín, A. Mueden, The creation of acid carbon surfaces by treatment with $\left(\mathrm{NH}_{4}\right)_{2} \mathrm{~S}_{2} \mathrm{O}_{8}$, Carbon 35 (1997) 1619-1626.

[49] F. Villacañas, M.F.R. Pereira, J.J.M. Órfão, J.L. Figueiredo, Adsorption of simple aromatic compounds on activated carbons, J. Colloid Interface Sci. 293 (2006) $128-136$.

[50] W.Z. Shen, Z.J. Li, Y.H. Liu, Surface chemical functional groups modification of porous carbon, Recent Pat. Chem. Eng. 1 (2008) 27-40.

[51] H.P. Boehm, Surface oxides on carbon and their analysis: a critical assessment, Carbon 40 (2002) 145-149.

[52] H. Guedidi, L. Reinert, J. Lévêque, Y. Soneda, N. Bellakhal, L. Duclaux, The effects of the surface oxidation of activated carbon, the solution $\mathrm{pH}$ and the temperature on adsorption of ibuprofen, Carbon 54 (2013) 432-443.

[53] A. Derylo-Marczewska, A. Swiatkowski, B. Buczek, S. Biniak, Adsorption equilibria in the systems: aqueous solutions of organics-oxidized activated carbon samples obtained from different parts of granules, Fuel 85 (2006) 410-417.

[54] A.N. Zhou, X.L. Ma, C.S. Song, Effects of oxidative modification of carbon surface on the adsorption of sulfur compounds in diesel fuel, Appl. Catal. B 87 (2009) 190-199.

[55] A.E. Aksoylu, M. Madalena, A. Freitas, M.F.R. Pereira, J.L. Figueiredo, The effects of different activated carbon supports and support modifications on the properties of Pt/AC catalysts, Carbon 39 (2001) 175-185.

[56] D.D. Do, A model for surface diffusion of ethane and propane in activated carbon, Chem. Eng. Sci. 51 (1996) 4145-4158.

[57] R. Ahmad, R. Kumar, Adsorption of amaranth dye onto alumina reinforced polystyrene, CLEAN: Soil, Air, Water 39 (2011) 74-82.

[58] B.V. Oepen, W. Kördel, W. Klein, Sorption of nonpolar and polar compounds to soils: processes, measurements and experience with the applicability of the modified OECD-Guideline 106, Chemosphere 22 (1991) 285-304.

[59] H.Y. Erbil, Surface Chemistry: Of Solid and Liquid Interfaces, Blackwell, Oxford, 2006.

[60] M. Singh, N.J. Zhou, D.K. Paul, K.J. Klabunde, IR spectral evidence of aldol condensation: acetaldehyde adsorption over $\mathrm{TiO}_{2}$ surface, J. Catal. 260 (2008) 371-379.

[61] Ö. Derelia, Y. Erdogdub, M.T. Gulluoglu, Study on molecular structure and vibrational spectra of (triphenylphosphoranylidene) acetaldehyde using DFT: a combined experimental and quantum chemical approach, J. Mol. Struct. 1012 (2012) 105-112. 